GALDINO, A. M. S.; LUZ, T. C.; AMORIM, D. C. G.

Experimentando e aprendendo: iniciação científica para crianças

DOI: $10.31416 /$ rsdv.v8i2.46

\title{
Experimentando e aprendendo: iniciação científica para crianças
}

\author{
Experimenting and learning: scientific initiation for children
}

GALDINO, Alerrandra Mikelli Soares. Graduanda em Licenciatura em Química. IF SERTÃO-PE, Campus Petrolina. Rua Maria Luiza de Araújo Gomes Cabral, S/N. Jardim São Paulo, Petrolina-PE, CEP 56.316- 686. Telefone: (87) 2101.4300 / E-mail: mikellialerrandra@gmail.com

LUZ, Thaliny da Cruz. Graduanda em Licenciatura em Química.

IF SERTÃO-PE, Campus Petrolina. Rua Maria Luiza de Araújo Gomes Cabral, S/N. Jardim São Paulo, Petrolina-PE, CEP 56.316-686. Telefone: (87) 2101.4300 / E-mail: thalinycruztcl2@gmail.com

\section{AMORIM, Delza Cristina Guedes. Mestre em Educação, Cultura e Territórios Semiáridos \\ IF SERTÃO- PE, Campus Petrolina. Rua Maria Luiza de Araújo Gomes Cabral, S/N. Jardim São Paulo, Petrolina- PE, CEP 56.316-686. Telefone: (87) 2101.4300 / E-mail: delza.cristina@ifsertao-pe.edu.br}

\section{RESUMO}

Este artigo relata a experiência de um projeto de extensão desenvolvido a partir da importância da iniciação científica para crianças, embasado na necessidade de oportunizar um ensino de ciências utilizando a experimentação. 0 projeto teve como objetivo geral desenvolver o espírito científico da criança, por meio da aplicação de experimentos. 0 método usado no desenvolvimento do projeto foi o da pesquisa-ação, de natureza qualitativa e aplicado numa instituição que acolhe meninas em situação de vulnerabilidade social, na faixa etária de 4 a 12 anos, nos turnos matutino e vespertino. As atividades foram desenvolvidas por meio da aplicação de experimentos caseiros e de baixo custo na ONG "Semente do Amanhã" na periferia da cidade de Petrolina. Os experimentos foram escolhidos, testados e realizados com 23 crianças seguindo uma sequência didática de acolhida, realização do experimento e avaliação da atividade. Foram realizados ao todo nove experimentos diferentes e evidenciou-se um despertamento nas crianças para irem além da curiosidade infantil conhecendo os aspectos científicos de cada atividade aplicadas ao cotidiano.

Palavras-chave: Alfabetização científica; Experimentação; Vulnerabilidade social; Iniciação científica.

\begin{abstract}
This article reports the experience of an extension project developed from the importance of scientific initiation for children, based on the need to provide opportunities for a science teaching using experimentation. The project had as general objective to develop the scientific spirit of the child, through the application of experiments. The method used in the development of the project was action research, qualitative in nature and applied in an institution that welcomes girls in situations of social vulnerability, aged 4 to 12 years, in the morning and old shifts. The activities were developed through the application of homemade and low-cost experiments in the ONG "Sementes do Amanhã" on the outskirts of the city of Petrolina. The experiments were chosen, tested and carried out with 23 children following a didactic sequence of welcoming, conducting the experiment and evaluating the activity. A total of nine different experiments were carried out and there was an awakening in children to go beyond childhood curiosity knowing the scientific aspects of each activity applied to daily life.
\end{abstract}

Keywords: Scientific literacy; Experimentation; Social vulnerability; Scientific initiation. 
GALDINO, A. M. S.; LUZ, T. C.; AMORIM, D. C. G.

Introdução

O presente artigo é resultado de um projeto de Extensão e teve como motivação o desejo de trabalhar a iniciação científica com crianças por meio de experimentos de baixo custo. É natural da criança construir ideias sobre o mundo ao seu redor mesmo que não esteja associando-as com a ciência. Essa forma de pensar, segundo Chassot (2018), pode ser bem explorada para que possibilite superar explicações animistas e místicas que as crianças possuem sobre determinados fenômenos. Para tanto, se faz necessário desenvolver habilidades intelectuais por meio de estratégias didáticas que oportunizem o raciocínio lógico e a capacidade crítica.

O ensino de ciências e o material didático disponibilizado na maioria das escolas é trabalhado de forma memorística e desconectado da realidade do aluno, não sendo, portanto, suficiente para desenvolver o espírito crítico da criança e sua atuação como ser pensante na sociedade.

De uma forma geral, a criança, mesmo escolarizada, não tem uma participação muito ativa na construção do seu próprio conhecimento por falta de atividades desafiadoras que instiguem a curiosidade natural e problematize situações do cotidiano. O projeto "Ensinando e aprendendo" voltado para promover a iniciação científica da criança no sentido de contribuir com o ensino de ciências buscou oportunizar o desenvolvimento da curiosidade infantil e do espírito investigativo por meio de vivências com experimentos de baixo custo usando produtos alternativos e de fácil acesso, os quais instigaram a contextualização de situações cotidianas a fenômenos científicos de forma lúdica.

Essa estratégia pedagógica se caracteriza como uma metodologia ativa que promove o envolvimento da criança durante a realização das atividades. Conforme Mattar (2017, p.21), as metodologias ativas proporcionam o envolvimento comportamental e psicológico. Ou seja, não podem apenas ser atividades de movimentação, mas também de processamento cognitivo que produz aprendizado.

A comunidade escolhida para aplicação do projeto foi a organização não governamental Instituto Cidadania Participativa com o nome de "Sementes do Amanhã", com dez anos de atuação no bairro Mandacarú, situado na zona leste, na periferia da cidade de Petrolina. Segundo a direção da instituição o bairro apresenta 
GALDINO, A. M. S.; LUZ, T. C.; AMORIM, D. C. G.

Experimentando e aprendendo: iniciação científica para crianças

problemas como saneamento básico, grande incidência de violência, tráfico e uso de drogas, exploração e abuso sexual e muitas crianças e adolescentes em situação de vulnerabilidade social. "A definição sobre vulnerabilidade remete à ideia de fragilidade e de dependência, que se conecta à situação de crianças e adolescentes, principalmente os de menor nível socioeconômico. Devido à fragilidade e dependência dos mais velhos, esse público torna-se muito submisso ao ambiente físico e social em que se encontra" ( FONSECA et al, 2013, p.259).

Dentro dessa situação social predominante no bairro, segundo Fonseca (et al, 2013, p.260), "os índices de violação dos direitos das crianças e dos adolescentes, no Brasil, ainda se apresentam elevados, mesmo que os números indiquem tendência de queda. As principais formas de transgressão dos direitos contra esse grupo são o abandono, o trabalho precoce a exploração sexual".

Atualmente frequentam a instituição em torno de 30 meninas, com a faixa etária de 4 a 12 anos, de segunda a sexta, durante o dia, as quais são divididas em turnos diferenciados se adequando ao cotidiano de tais, com isso as crianças que estudam a tarde ficam na instituição no turno da manhã e as que estudam de manhã vão à tarde. Essas crianças são encaminhadas pela própria comunidade e pelo conselho tutelar. $O$ instituto proporciona para as crianças recreação, contribuem com o reforço escolar, além de alimentação. Também desenvolvem parcerias com instituições tanto em Petrolina-PE, quanto em Juazeiro-BA.

A estrutura física da instituição possui uma sala com cadeiras escolares, uma sala para futuro laboratório de informática, e ainda salas para refeitório e coordenação. Conta com quatro pessoas responsáveis na direção e coordenação e pessoas voluntárias no apoio, e suporte pedagógico. A escolha dessa instituição visou contribuir socialmente para tornar a ciência acessível a todos, proporcionando o desenvolvimento da aprendizagem das crianças que frequentam a casa.

O projeto partiu do pressuposto de que a estimulação da criança por meio de problematizações e desafios, potencializam o desenvolvimento cognitivo e a visão crítica das mesmas, e, teve como objetivo geral, desenvolver o espírito científico da criança por meio da aplicação de experimentos nos quais podiam usar a observação, contextualização, registro dos fatos e comprovação de hipóteses, fazendo aplicações na sua realidade de forma crítica. E como objetivos específicos:1. Propor soluções de forma contextualizada para problematizações levantados a partir dos temas 
GALDINO, A. M. S.; LUZ, T. C.; AMORIM, D. C. G.

Experimentando e aprendendo: iniciação científica para crianças

geradores. 2. Observar e descrever de forma oral e escrita os fenômenos vivenciados nos experimentos. 4. Discutir resultados e conclusões a partir dos experimentos aplicados de forma a construir e consolidar conceitos científicos. 5. Aplicar os conceitos construídos na realidade cotidiana.

Com o intuito de prevalecer o caráter científico e social presentes nos objetivos contidos com a realização do projeto, foi necessário uma revisão bibliográfica utilizando os trabalhos de autores que reforçam metodologias ativas, interdisciplinaridade, o ensino adequado a estudantes em vulnerabilidade, e alfabetização científica, entre eles estão: Silva, Beuren, Lorenzon (2016); Zanon e Freitas (2007); Chassot (2018); Trindade (2008); Ahlert, Wildner, Padilha (2017); Morán (2015); Fonseca (2013).

O projeto apoiou seu aporte teórico nos conceitos de letramento e alfabetização científica para a iniciação em Ciências, como também no processo investigativo por meio da experimentação e interdisciplinaridade, e, ainda nos conceitos de metodologias ativas. Por escolher a ONG "Sementes do Amanhã" como espaço de realização do projeto, a abordagem sobre a vulnerabilidade social de crianças e adolescentes foi também discutida.

\section{Metodologia}

0 método usado no desenvolvimento do projeto foi o da pesquisa-ação por entender conforme Thiollent (2000), que seus objetivos podem visar entre outros resolver um problema prático, como também desenvolver a consciência coletiva a respeito de problemas enfrentados e, ainda, a produção de conhecimento. Enfatizando a importância da pesquisa-ação em atividades extensionistas, Thiollent (2008), diz que por meio da mesma se aprende a identificar e resolver problemas coletivamente, com observação e ação sobre o entorno o que promove o compartilhamento de informações e aplicação de iniciativas concretas.

Foram feitas as devidas orientações relativas ao comitê de ética da instituição em relação aos termos de assentimento das crianças juntamente com os responsáveis, o que trouxe uma segurança ao projeto desenvolvido. 
GALDINO, A. M. S.; LUZ, T. C.; AMORIM, D. C. G.

Experimentando e aprendendo: iniciação científica para crianças

As abordagens foram feitas por meio da realização de experimentos científicos de forma interdisciplinar trabalhando e discutindo problemas envolvendo fenômenos científicos e sociais como forma de introduzir os participantes no universo da Ciência, Tecnologia e Sociedade. Para planejamento e avaliação das atividades foram discutidas e organizadas estratégias e recursos necessários para o andamento das mesmas, como também avaliação e elaboração de resumos e relatório.

A aplicação dos experimentos na instituição foi feita observando as seguintes etapas:

\section{Reunião para estudo}

Para um maior aprofundamento da temática foram inicialmente realizados estudos com a equipe envolvida: orientadora, uma bolsista e uma voluntária, alunas da Licenciatura em Química. Os estudos abordaram a fundamentação teórica e trabalhos semelhantes com três temáticas: Vulnerabilidade social na infância e adolescência, atividades experimentais para crianças com enfoque investigativo e interdisciplinar e ainda o uso de metodologias ativas na aprendizagem. Os estudos deram embasamento para a escolha e organização dos experimentos que foram usados com as crianças.

Por tratar como objetivo principal a alfabetização científica de crianças em vulnerabilidade social, esse projeto buscou ao máximo utilizar técnicas que viessem a contribuir educacionalmente e socialmente a todos os envolvidos. Para isso foi necessário realizar reuniões semanais nas quais eram debatidas as ações que melhor viessem a contribuir com o andamento das aulas.

A partir da realização das aulas eram vistos pontos positivos e negativos, e com a observação dos mesmos eram propostas sugestões que viessem a sempre está melhorando os procedimentos educacionais, por meio da utilização do estudo de obras de autores que já trabalharam com o mesmo enfoque. Além de serem escolhidos os experimentos, ressaltando sempre que os mesmos deveriam ser de baixo custo e que não viesse a causar danos físicos, também era pensada a sequência didática a ser aplicada em cada aula. Essas reuniões contribuíram para o melhor andamento das aulas, que disponibilizaram ensinamentos científicos e sociais as crianças, e também para o aperfeiçoamento profissional, ressaltando também a contribuição perante a comunidade que viam por meio da nova perspectiva das 
GALDINO, A. M. S.; LUZ, T. C.; AMORIM, D. C. G.

Experimentando e aprendendo: iniciação científica para crianças

crianças que a ciência está presente na vida de todos, e que o respeito em comunidade é de extrema importância para o bem estar dos mesmos.

\section{Organização de grupos}

Tendo em vista a necessidade de troca de turnos, foi decidido que para melhor andamento do projeto era bem visto que a cada semana fosse passado experimentos distintos, alternando o horário das aulas, contemplando todas as crianças que frequentam a casa.

Inicialmente foi proposto que para melhor andamento das aulas era necessário a separação das crianças por faixa etária, justamente por se tratar de assuntos científicos tendo em vista que o desfecho dos experimentos e assuntos abordados poderiam não ser melhor entendidos por todas as crianças, ressaltando que as mesmas têm idades e nível de ensino distintos. Ademais, pelo local escolhido não obter o suporte necessário para a realização da ideia proposta, as primeiras aulas foram realizadas com todas as crianças juntas, utilizando experimentos e vocabulário que viesse a ser aproveitados por todas.

\section{Aplicação dos experimentos}

Para melhor andamento das aulas foram propostas medidas que viessem a ajudar as crianças a se sentirem confortáveis, contribuísse com a dinâmica das aulas e realização dos experimentos. Ressaltando que por se tratar de um projeto que trabalhava com a iniciativa de alfabetizar cientificamente e socialmente crianças em vulnerabilidade, era de extrema importante a utilização de metodologias ativas que as deixassem inteiramente acolhidas para sua participação durante os encontros, levando noções de convívio social e as adentrando no domínio científico junto a isso, ademais era realizado durante as reuniões o debate decorrente de como o espaço da ONG poderia ser melhor integrado ao andamento do projeto, observando sempre os melhores meios de deixar todos os envolvidos em harmonia.

Sendo assim, as aulas tinham a duração de uma hora e meia e eram divididas nas seguintes etapas:

\section{a) Acolhida}

Para cuidado em relação ao bom andamento do projeto, utilizou-se a projeção de um relacionamento saudável entre todos os envolvidos, sendo assim, atividades lúdicas que ensinassem noções de amizade, respeito para com o próximo e com meio 
GALDINO, A. M. S.; LUZ, T. C.; AMORIM, D. C. G.

ambiente, foram executadas no início de todas as aulas com o objetivo de integrar as crianças e introduzir na temática do experimento.

Das atividades em destaque, estavam músicas e brincadeiras que fizessem com que a interação fosse iniciada, formando um vínculo entre os participantes, deixando as crianças confortáveis para tratar de assuntos tanto científicos, quanto sociais. Ao final de toda acolhida eram debatidas as noções sociais que todo exercícios trazia, por exemplo, ao levar a versão da cantiga "Atirei o pau no gato", modificada para "Não atirei o pau no gato", com teor de cuidado e respeito para com os animais, era observado e conversado em sala de aula o porquê dessa atividade ter sido levada e como ela foi mudada em relação à versão anterior.

\section{b) Experimentação}

Para que houvesse um melhor aproveitamento de noções já existente pelas crianças, tomando como contrapartida idealizações e conhecimentos prévios, era de extrema importância fazer com as mesmas enxergassem onde está a ciência presente em sua rotina e como ela ocorre. Inicialmente após cada acolhida, a continuidade da aula era referente aos ensinos científicos, onde as crianças eram questionadas sobre atividades executadas em seu cotidiano e o que elas entendiam sobre as mesmas, as instigando a criarem hipóteses e visões às quais eram analisadas antes, durante e depois da realização do experimento, tendo em vista como as crianças poderiam ajudar na realização do experimento e quais análises eram de extrema importância a serem passadas para as mesmas.

Foram realizados 9 experimentos sendo eles diferentes entre si, com o intuito de levar as crianças noções distintas sobre ciências: Experimentos realizados: Vulcão; Fazendo slime; Ilusão inversa e construindo um projetor; Densidade; Areia movediça; Filtro caseiro; Museu da natureza; Enchendo o balão sem assoprar e Explosões no leite.

Decorrente das discussões levantadas, era visto que algumas das crianças ainda tinham idealizações fantasiosas sobre reações e identificações científicas já vivenciadas pelas mesmas, sendo assim era posto como objetivo ensinar essas noções tendo como resposta a ciência. Posteriormente, para exemplificar e instigar mais ainda os alunos, era executado um experimento que viesse a mostrar com contexto científico como esses acontecimentos já vivenciados eram realizados, sempre pondo em destaque que esses experimentos poderiam ser realizados fora de laboratórios, 
GALDINO, A. M. S.; LUZ, T. C.; AMORIM, D. C. G.

Experimentando e aprendendo: iniciação científica para crianças

além de demonstrar quais seriam os procedimentos realizados por cada cientista e quais cuidados eram importantes.

Durante e após a realização da experimentação, as crianças eram solicitadas a falar sobre o fenômeno observado e as conclusões que chegaram. Por fim elas desenhavam e ou escreviam sobre a experiência. Essa abordagem foi promovendo o hábito de escutar, opinar, desenvolvendo o raciocínio lógico. Todos os experimentos eram discutidos durante as reuniões, analisando quais iriam ser melhor entendidos pelas crianças e qual a sequência didática que seria abordada.

\section{c) Avaliação}

Para analisar quais os ensinamentos que as crianças vinham a entender, por meio de perguntas as crianças eram estimuladas a relatar suas impressões, sensações e sentimentos. Dessa forma as crianças puderam desenvolver competências socioemocionais e ainda de comunicação e escuta ativa.

As atividades decorrentes dos resumos ou desenhos também desempenhavam a finalidade de identificar se as mesmas realmente estavam compreendendo cientificamente, além de perguntas que eram feitas durante o procedimento didático de cada encontro. Essas avaliações eram voltadas especificamente às crianças, para tanto foram analisadas as perguntas orais e registros escritos ou desenhados no caderno de cada uma.

\section{Resultados e Discussão}

Para que houvesse êxito quanto aos resultados, foi atribuída uma ferramenta de avaliação do desempenho da equipe do projeto, denominado diário de campo. 0 mesmo deveria constar os relatos sobre o ambiente físico e emocional da instituição, descrição das atividades realizadas, materiais utilizados, impressões e percepções pessoais, reflexões sobre os experimentos realizados e sugestões para as próximas etapas. Através das descrições contidas no diário de campo, eram analisadas as necessidades de aprimoramento quanto a aplicação dos experimentos e o que deveria ser mantido.

Com o intuito de analisar se as crianças compreendiam os conhecimentos passados em cada aula eram realizadas perguntas durante todo o experimento, com isso as respostas eram comparadas em relação às intuições já presentes no saber de 
cada uma e como esses eram modificados após a explicação, favorecendo portanto a ideia de que "as metodologias ativas são formas de desenvolver o processo ensinoaprendizagem com maior envolvimento do estudante, favorecendo o pensamento crítico e a autonomia", (AHLERT, WILDNER E PADILHA, 2017, p.9).

$\mathrm{Na}$ descrição das etapas de planejamento, organização e avaliação foram especificados:

\title{
1. Adequação dos experimentos ao público alvo
}

Todos os experimentos foram escolhidos levando em consideração a idade e escolaridade das crianças, sendo assim, os experimentos foram pensados de modo a seguir uma abordagem interdisciplinar o que fez com que as crianças formulassem respostas intuitivas, mas também respostas coerentes com o experimento abordado.

Segundo Chassot (2018), ainda é preciso considerar que a iniciação científica por meio de atividades experimentais deve buscar uma abordagem interdisciplinar, na qual a Ciência é estudada de maneira inter- relacionada com a tecnologia e a sociedade. A interdisciplinaridade antes de tudo é uma atitude frente ao conhecimento. Conforme Trindade (2008, p.82),

\begin{abstract}
A prática interdisciplinar pressupõe uma desconstrução, uma ruptura com o tradicional e com o cotidiano tarefeiro escolar. 0 professor interdisciplinar percorre as regiões fronteiriças flexíveis onde o "eu" convive com o "outro" sem abrir mão de suas características, possibilitando a interdependência, o compartilhamento, o encontro, o diálogo e as transformações. Esse é o movimento da interdisciplinaridade caracterizada por atitudes ante o conhecimento.
\end{abstract}

A abordagem desse projeto utilizou esse caráter interdisciplinar por meio de atividades experimentais como estratégia didática como forma de fomentar o diálogo e as interações durante as aulas.

2. Dificuldades apresentadas pelas crianças durante a aplicação das atividades

$\mathrm{Na}$ busca de trabalhar de forma investigativa, algumas dificuldades foram encontradas na execução do projeto, tais como: organização do local onde as aulas eram realizadas, desconhecimento de assuntos específicos abordados, inquietude em detrimento do contexto em que as crianças se encontravam. No entanto, nenhuma dessas dificuldades foi diretamente ligada ao experimento em si, e, sim, a outros fatores intervenientes. 
GALDINO, A. M. S.; LUZ, T. C.; AMORIM, D. C. G.

Experimentando e aprendendo: iniciação científica para crianças

Conforme Silva, Beuren e Lorenzon (2016, p.8), “[...]Investigar é buscar estratégias para resolver nossos próprios problemas", e, essa forma de abordagem permite contextualizar as situações cotidianas das crianças oportunizando a reflexão sobre a intervenção na realidade.

A iniciação científica trabalha o processo investigativo o qual deve ser aplicado de forma didática a fim de possibilitar a compreensão e a reflexão sobre a realidade do mundo. A atividade experimental no ensino de Ciências não resume todo o processo investigativo. Não adianta usar atividades experimentais apenas para ilustrar ou comprovar teorias, estas atividades devem favorecer a construção do conhecimento de forma crítica (ZANON E FREITAS, 2007 p. 94).

Ademais, utilizando de metodologias específicas e adequação ao local, foi possível realizar os experimentos em relação ao objetivo posto na execução do projeto, levando em conta o contexto em que o mesmo foi realizado e com a utilização de materiais alternativos e de baixo custo. Sendo assim, foi possível trabalhar a investigação por meio das atividades realizadas, por meio da contextualização e problematização.

\section{Contribuições para a formação docente e para a instituição.}

Para todos os envolvidos na realização do projeto teve contribuiçõos em relação a obtenção de conhecimentos científico e sociais, seja por parte das crianças que receberam as aulas e também por parte dos participantes que tiveram adicional de conhecimentos pedagógicos inseridos em sua vida profissional, curricular.

Com o intuito de seguir a ideia de que "Para assegurar a pertinência dessas ações em relação às prioridades, uma exigência básica é conhecimento e reconhecimento da demanda de crianças e adolescentes com relação aos fatores que promovam e protejam seu desenvolvimento, como saúde, educação e lazer, entre outros" (FONSECA et al, 2013, p.3). A comunidade também teve uma parcela de favorecimento, por meio do novo olhar científico e social dos envolvidos. As crianças estavam trabalhando a ciência de forma lúdica e aplicada ao cotidiano.

Uma contribuição pertinente foi a confecção de um "Manual de experimentos" com todos os experimentos compilados o qual foi distribuído para alguns dos responsáveis dos menores na instituição, a fim de levar aos mesmos uma visão da possibilidade da iniciação científica com materiais encontradas em seu cotidiano, podendo o mesmo ser usado em outros momentos na instituição. 
GALDINO, A. M. S.; LUZ, T. C.; AMORIM, D. C. G.

Experimentando e aprendendo: iniciação científica para crianças

Para melhor detalhamento das etapas de análise em relação à aplicação dos experimentos e procedimentos educacionais foram especificados:

4. As principais soluções que as crianças levantaram para as problematizações dos experimentos aplicados

Segundo Morán (2015, p. 18):

\begin{abstract}
Alguns componentes são fundamentais para o sucesso da aprendizagem: a criação de desafios, atividades, jogos que realmente trazem as competências necessárias para cada etapa, que solicitam informações pertinentes, que oferecem recompensas estimulantes, que combinam percursos pessoais com participação significativa em grupos, que se inserem em plataformas adaptativas, que reconhecem cada aluno e ao mesmo tempo aprendem com a interação, tudo isso utilizando as tecnologias adequadas.
\end{abstract}

Por esse motivo inicialmente eram feitas perguntas sobre o tema abordado, e em sua maioria as respostas expostas não provinham da ciência, porém vale ressaltar que apesar de alguns diálogos proveniente das crianças terem essas indagações foi observado que de alguma forma a ideia científica também era presente, mas de uma forma não trabalhada. Por esse motivo durante a realização dos experimentos acompanhados de explicações mais científicas as crianças tinham amadurecimento de seus saberes, ademais por se tratar de turmas com idades e ensinos diferentes era visto o diferencial de aprendizagem entre elas.

5. Como descreveram de forma oral e escrita e por meio de desenhos os fenômenos vivenciados nos experimentos

Concorrem para a promoção da autonomia as atividades de aprendizagem que possibilitam, por exemplo, conforme Bzuneck e Guimarães (2010), que, em relação a um dado comportamento, haja envolvimento pessoal, baixa pressão e alta flexibilidade em sua execução, e percepção de liberdade psicológica e de escolha.

Chegando nas atividades finais que proviam de perguntas e resumos feitos através de desenhos ou escrita, os alunos mostravam quais conhecimentos haviam adquirido, tendo portanto notado um grande avanço em relação aos assuntos abordados e percepção de encantamento decorrente dos experimentos realizados.

Os desenhos das crianças menores (4-6 anos) continuaram a ser fantasiosos, porém não mais apenas com idealizações inexistentes. As crianças entre 7-10 anos eram mais detalhistas no desenho e na escrita, descrevendo e interpretando o fenômeno observado. 
GALDINO, A. M. S.; LUZ, T. C.; AMORIM, D. C. G.

Experimentando e aprendendo: iniciação científica para crianças

Contemplando Berbel (2011, p. 29), “Podemos entender que as Metodologias Ativas baseiam-se em formas de desenvolver o processo de aprender, utilizando experiências reais ou simuladas, visando às condições de solucionar, com sucesso, desafios advindos das atividades essenciais da prática social, em diferentes contextos". Nesse sentido, todos os experimentos advinham de materiais que as crianças já tinham vivência fora da sala, a fim de criar um relacionamento entre os mesmos e a ciência.

A forma como aplicaram os conceitos ao cotidiano foi por meio de comparações do que viam e contextualizavam durante os experimentos e realidades vivenciadas pelas mesmas.

\section{Experimentos com melhores resultados}

Todos os experimentos obtiveram resultados bons em relação à iniciação científica das crianças, porém é importante ressaltar que as mesmas não intencionalmente selecionavam quais procedimentos mais the chamavam atenção e a partir disso alguns deles não se destacaram tanto quanto outros.

Com intuito de demonstrar quais experimentos foram melhor abordados com as crianças, levamos em conta aulas nas quais as mesmas tiveram mais foco e instigaram mais perguntas e curiosidades em relação ao assunto apresentado, além da observação de seus detalhamentos decorrente ao que entenderam apresentados em seus cadernos. Ressaltando que durante todos os experimentos foram levadas medidas que viessem a incluí-las de algum modo nos procedimentos, sejam elas relatando o que estava acontecendo ou até mesmo realizando a atividade. Trindade (2008, p.65), relata:

\footnotetext{
A história da ciência possibilita a construção e uma compreensão dinâmica da nossa vivência, da convivência harmônica com o mundo da informação, do entendimento histórico da vida científica, social, produtiva da civilização, ou seja, é um aprendizado com aspectos práticos e críticos de uma participação no romance da cultura científica, ingrediente primordial da saga da humanidade.
}

O que por sua vez foi compilado aos conhecimentos advindos na história da ciência e que é de extrema importância para a humanidade, por se tratar de conhecimentos voltados a "água" e “vulcanismo". Portanto são destacados o experimento do "Vulcão" e "Filtro caseiro", como vivências que mais vieram a causar bom contato das crianças com a ciência. 
GALDINO, A. M. S.; LUZ, T. C.; AMORIM, D. C. G.

Experimentando e aprendendo: iniciação científica para crianças

Essa aula foi realizada apenas na sala de aula, onde o assunto em destaque foi "vulcanismo", que teve como atividade de prática a confecção de um vulcão e demonstração de uma erupção. Ao final foi observado que as crianças compreenderam os conhecimentos sobre erupções vulcânicas, e como esse fenômeno natural ocorre. Também foi associado com situações que podem acontecer no dia a dia e que podem provocar reações.

\section{Quadro 01. Experimento: Vulcão}

\section{Objetivo}

- Compreender os fenômenos vulcânicos e associar a reações ocorrentes na vivência das crianças.

Materiais necessários

- Bicarbonato de sódio

- Tinta vermelha (corante alimentício)

- Água

- Detergente

- Vinagre

- Cartolina

- Massa de modelar

- $\quad$ Recipiente vazio (garrafa pet)

- Bandeja

\section{Passo a passo:}

$1^{\circ}$ Faça um cone com a cartolina e corte a parte de cima. Coloque por dentro um recipiente vazio. Coloque massinha de modelar marrom na cartolina para ficar parecido com uma montanha. A apoiar a construção em uma bandeja.

$2^{\circ}$ Coloque no recipiente vazio dentro da cartolina, bicarbonato de sódio, tinta vermelha, água e uma gota de detergente;

$3^{\circ}$ Misture tudo e deixe que a criança coloque a gota de vinagre.

\section{Perguntas}

a) Quem já viu a imagem de um vulcão?

b) Por que a lava sai do vulcão?

c) 0 que aconteceu no experimento?

d) Por que o líquido foi expulso para fora do vulcão?

Fonte: 1-Toda criança pode aprender. Disponível em $<$ https://googleweblight.com/i?u=https://labedu.org.br/5-atividadescientificas-para-fazer-com-as-criancas/\&hl=pt- BR>. Acesso em: 12 abr. 2019. 2-BASTOS, Edson. Atividades de ciências da natureza. Disponível em <http://www.cienciamao.usp.br/tudo/exibir.php?midia=Icn\&cod=_simulacaode umvulcao>. Acesso em: 12 abr. 2019. (Adaptado) 
Quadro 02 - Experimento: Filtro caseiro

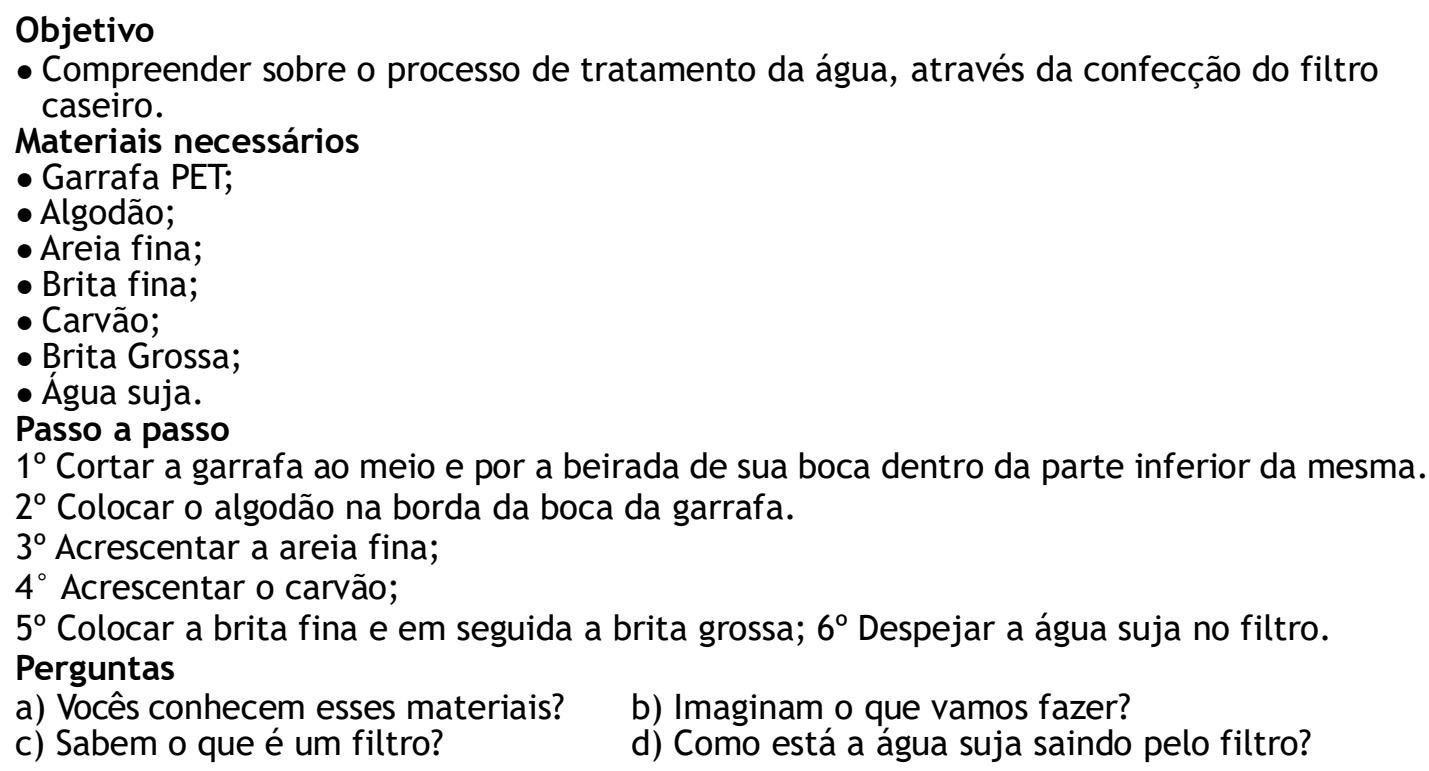

Fonte: Adaptado de anotações de aula experimental. IF Sertão-PE

Essa aula foi realizada no pátio da instituição com intuito de tornar o encontro mais acolhido e dinâmico, a atividade escolhida foi relacionada a música, na qual os alunos junto com os bolsistas controlaram músicas infantis, tendo como finalidade criar um espírito de companheirismo e animação entre as crianças. A seguir foi dada explicações sobre a importância da água e o cuidado que devemos ter ao utilizá-la, além de passar conhecimentos voltados ao tratamento da mesma, incluindo a utilização de filtros e como eles são fabricados, por fim houve a fabricação de um filtro caseiro. Sendo assim foi observado ao final do encontro que as crianças compreenderam a utilidade de um filtro e perceberam a necessidade do tratamento da água para o consumo humano.

\section{Experimento com que apresentou dificuldades}

Por se tratarem de atividades nas quais as crianças não tinham contato, era perceptível que as mesmas tinham extrema ansiedade para começar as aulas, principalmente para chegar a etapa de realização dos experimentos, por esse motivo houve alguns experimentos que tiveram seu andamento dificultado, destacando que nesses encontros as crianças se mostraram muito agitadas e desatentas, desmerecendo o processo que consistia em análise do tema, levantamento de questões norteadoras e observação dos fatos.

Por se tratar de encontros realizados em um local com contexto de 
GALDINO, A. M. S.; LUZ, T. C.; AMORIM, D. C. G.

Experimentando e aprendendo: iniciação científica para crianças

vulnerabilidade, o humor dos alunos também vinha a interferir as aulas em alguns momentos, e as mesmas ficavam dispersas, desestabilizando não só a obtenção de seu próprio conhecimento, mas também de outras crianças envolvidas.

As crianças que frequentam a instituição onde foi desenvolvido o projeto encontra- se relacionada aos riscos familiares, de moradia e seus desdobramentos que configuram um quadro alto de vulnerabilidade social. Conforme Fonseca (et al, 2013, p.260).

Existem componentes importantes para avaliar as condições de maior ou de menor vulnerabilidade social, individual ou coletiva. Entre esses componentes podem ser citados: o acesso aos meios de comunicação, a escolarização, a disponibilidade de recursos materiais, a autonomia para influenciar nas decisões políticas e a possibilidade de enfrentar barreiras culturais e de estar livre de coerções violentas ou poder defender-se delas.

Visando contribuir para o enfrentamento nessa perspectiva social, o projeto, por meio de aplicação de atividades experimentais como iniciação científica, pretendeu ser um importante elo na consecução de melhorias educacionais e pessoais para as crianças e todos os envolvidos diretamente com estas.

Em destaque o experimento que não teve seu andamento como esperado, foi o "Fabricação de slime", como relatado anteriormente neste encontro houve problemas em relação ao comportamento das crianças que acarretam dificuldade de compreensão.

Essa aula realizada na sala e no pátio, com ajuda de alguns objetos da instituição, para a realização da acolhida. Sendo assim, inicialmente foi feita uma dinâmica chamada de "Atravessando os obstáculos", com intuito de instigar os alunos a trabalharem em equipe, dentre as outras questões, como orientação espacial. Posteriormente foi dada uma aula sobre algoritmo e elasticidade, colocando em prática com a fabricação de slime.

Ao final foi observado que as crianças entenderam o que é elasticidade e se divertiram com a produção do slime. Porém é destacado que as mesmas estavam extremamente agitadas, focando apenas na produção do slime e não adquirindo totalmente os conceitos de elasticidade e algoritmo. 


\section{Quadro 03. Experimento: Fabricação de slime}

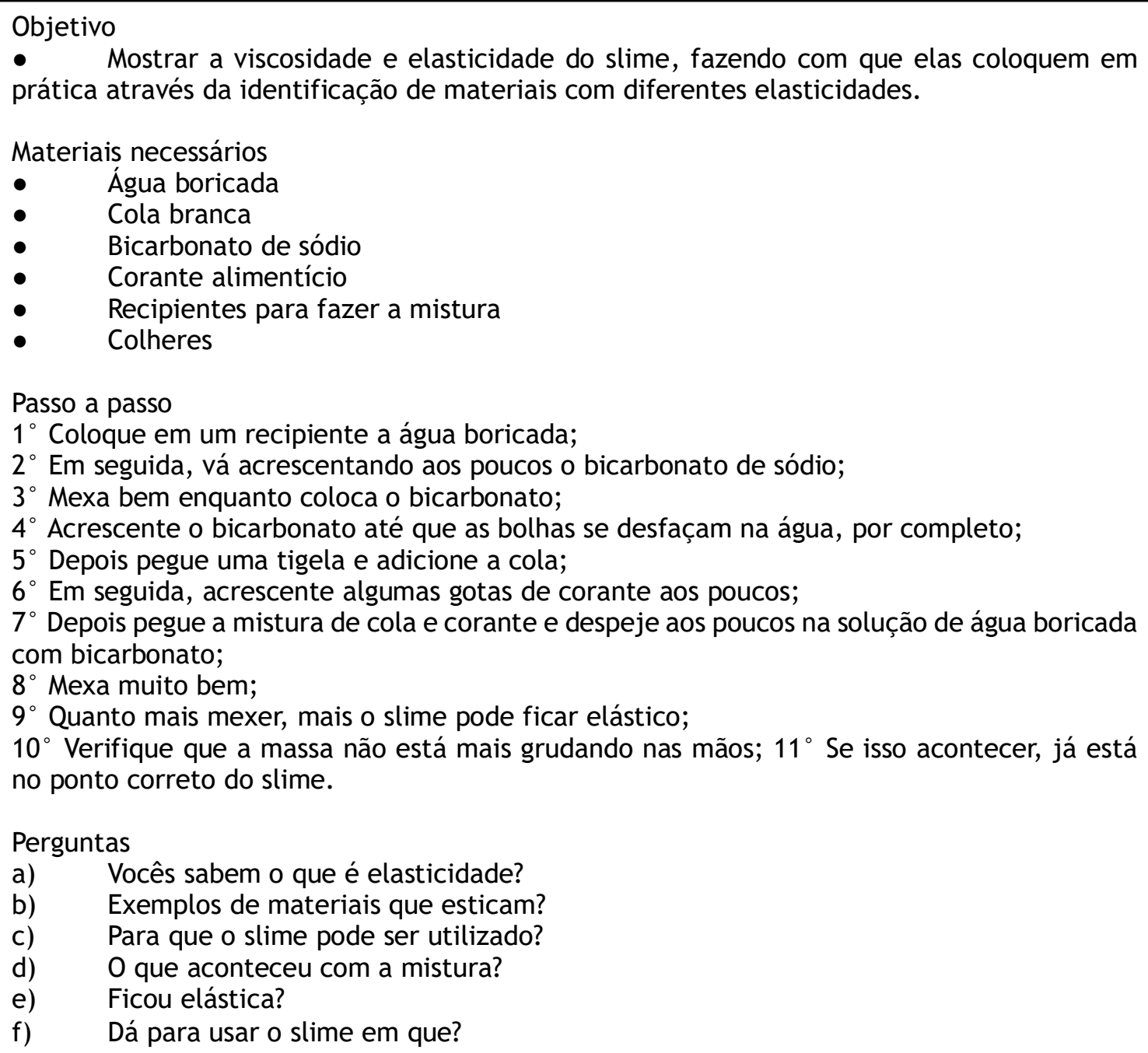

a) Vocês sabem o que é elasticidade?

b) Exemplos de materiais que esticam?

c) Para que o slime pode ser utilizado?

d) $\quad 0$ que aconteceu com a mistura?

e) Ficou elástica?

f) Dá para usar o slime em que?

Fonte: 1-DECORAFACIL. Como fazer slime: 9 receitas e maneiras para você tentar. Disponível em <https://www. decorfacil.com/como-fazer-slime/>. Acesso em: $12 \mathrm{abr}$. 2019. 2-DIAS Diogo. Experimento: produção de geleca. Disponível em <https://www.manualdaquimica.com/experimentos-quimica/experimento-producaogeleca.htm>. Acesso em: 12 abr. (Adaptado)

\section{Culminância}

Ao final dos encontros foi realizada uma culminância, na qual as próprias crianças dessem explicações sobre um determinado tema e realizasse um experimento. Nesse último encontro foi possível ver o quanto elas estavam animadas em colocarem em prática noções sobre a ciência que tinham observado durante as aulas, além do momento levar consigo a exposição de todos os experimentos realizados durante o projeto, com o intuito de destacar que a ciência está por toda parte e todos são capazes de entendê-la e usada ao seu favor, e, que todos podem 
GALDINO, A. M. S.; LUZ, T. C.; AMORIM, D. C. G.

Experimentando e aprendendo: iniciação científica para crianças

se tornar cientistas. Nesse momento foi possível perceber a importância da utilização de metodologias ativas.

Segundo Ahlert, Wildner e Padilha (2017, p.9),

[..] metodologia ativa pode ser definida como o conjunto de atividades que ocupa o estudante a fazer algo ao mesmo tempo em que deve pensar sobre o que está fazendo. [...] As estratégias para conseguir a aprendizagem ativa são várias. Todas, porém, provocam as funções mentais de pensar, raciocinar, observar, refletir, entender e combinar.

Na promoção de uma participação ativa das crianças, segundo Morán, (2015, p. 17), é necessário:

Se queremos que os alunos sejam proativos, precisamos adotar metodologias em que os alunos se envolvam em atividades cada vez mais complexas, em que tenham que tomar decisões e avaliar os resultados, com apoio de materiais relevantes. Se queremos que sejam criativos, eles precisam experimentar inúmeras novas possibilidades de mostrar sua iniciativa.

Ao final da aplicação do projeto, foi possível observar, por meio de atividades realizadas pelas crianças e indagações feitas durante as aulas, que as mesmas, aos poucos criaram familiaridade com os assuntos abordados e curiosidade para entender sobre o andamento de experimentos, com materiais alternativos, feitos pelas bolsista, juntamente com a participação ativa delas, principalmente no momento da culminância no último encontro, no qual foi visto em destaque o quanto as crianças estavam amadurecidas em relação a seus olhares científicos.

Os experimentos realizados pelas crianças no momento da culminância foram: "Explosão no leite" e "Enchendo o balão sem assoprar". Ao realizarem essas práticas as crianças explicaram como elas ocorrem e como esse contexto era aplicado socialmente na vida delas. Inicialmente foram selecionadas duas crianças em cada turno para receberem a explicação e realizarem o experimento primeiro para aprender e depois fazer para os colegas. As crianças selecionadas foram as que mais interagiam durante os experimentos. Foram confeccionados jalecos de TNT e as crianças vestiram o jaleco e fizeram os experimentos com muita propriedade e as colegas ficaram bem atentas e entusiasmadas. Esse foi um ponto alto da culminância.

No momento do experimento na culminância, as crianças observaram como algumas misturas entre diferentes substâncias não podem ser vistas a olho nu, mas que a presença de um diferente componente pode modificar o visual dessa mistura. 
GALDINO, A. M. S.; LUZ, T. C.; AMORIM, D. C. G.

Experimentando e aprendendo: iniciação científica para crianças

Quadro 04. Experimento: Explosão no leite

\section{Objetivo}

- Perceber como alguma substância se repelem e se atraem e interferem na estrutura física ocasionando transformações visuais.

Materiais necessários

- Leite;

- Detergente;

- Corante colorido;

- Recipiente transparente.

Passo a passo

$1^{\circ}$ Despejar o leite no recipiente;

$2^{\circ}$ Pingar corante no leite;

$3^{\circ}$ Colocar detergente aos poucos.

Perguntas

a) $\mathrm{O}$ que aconteceu?

b) Por que o corante se espalhou?

c) Vocês viram a gordura no leite?

Fonte: Adaptado de anotações de aula experimental. IF Sertão-PE.

\section{Quadro 05. Experimento: Enchendo o balão sem assoprar}

\section{Objetivo}

- Analisar a transformação e mistura de substâncias, através da produção do gás carbono.

Materiais necessários

- Vinagre;

- Bicarbonato de sódio;

- Garrafa pet;

- Bola de assopro.

Passo a passo

$1^{\circ}$ Despejar o vinagre na garrafa pet;

$2^{\circ}$ Colocar o bicarbonato de sódio no balão e fixar a boca do balão na garrafa; $3^{\circ}$ Derramar o bicarbonato na garrafa.

Perguntas

a) O bicarbonato sumiu de dentro da garrafa?

b) $\mathrm{O}$ que foi produzido através da mistura?

c) Como o balão encheu?

Fonte: Adaptado de anotações de aula experimental. IF Sertão-PE.

Nesse experimento as crianças compreenderam que na natureza nada se perde tudo se transforma, e observaram como pode ser produzido o gás carbono e como isso se aplica no cotidiano. A culminância encerrou com momento para fotos e lanche.

Permaneceram até o final do projeto 23 crianças, com idades de 4 a 12 anos, sendo a maioria entre 7 e 8 anos, onde, as principais contribuições sociais, foram as interações dessas envolvendo ciências e noções de cidadania, visto que as mesmas na maioria do tempo faziam apenas atividades recreativas. Tal interação também contribuiu com o desenvolvimento escolar das mesmas, pois muitas associavam 
conteúdos já estudados em suas instituições de ensino, com os experimentos.

Para os extensionistas houve o engrandecimento profissional que os fizeram vivenciar aulas com um público específico, utilizando o estudo de autores renomados que vieram a aprimorar todo o trabalho realizado.

\section{Considerações finais}

O projeto de extensão "Experimentando e aprendendo: Iniciação científica para crianças" teve seu embasamento no ensino de ciências utilizando a experimentação para todos os envolvidos. Tendo em

vista que os conhecimentos científicos e sociais são de extrema importância para o crescimento pessoal do ser humano, os objetivos propostos foram alcançados e as dificuldades foram ultrapassadas tendo o projeto concluído como uma experiência de grande relevância social e educacional voltada para crianças em situação de vulnerabilidade social e tendo como foco a iniciação científica.

Utilizando materiais caseiros e de baixo custo foi possível fazer contextualizações e problematizações por meio dos experimentos, instigando as crianças a pensar, propor soluções e ainda aplicar os saberes ao seu cotidiano, ampliando os conhecimentos prévios e despertando para o fazer ciência.

Além das crianças, o projeto trouxe um crescimento profissional na formação docente que as bolsistas tiveram durante toda a realização das atividades, incluindo a culminância e o manual de experimentos que foi disponibilizado para a comunidade com finalidade de ser utilizado posteriormente pelas próprias crianças e seus familiares.

A realização do projeto também despertou o desejo de ter a mesma experiência numa escola de ensino fundamental, aplicando experimentos dentro dos conteúdos trabalhados nas aulas de ciências.

\section{Agradecimentos}

Ao IF Sertão-PE, campus Petrolina; Ao PIBEX e a ONG Sementes do amanhã.

\section{Referências}

AHLERT, Edson Moacir; WILDNER, Maria Claudete Schorr; PADILHA, Teresinha Aparecida Faccio. (Orgs.) Metodologias Ativas de Ensino e Aprendizagem. IN: Anais do II Seminário de Educação Profissional, 11 e 12 de maio de 2017, Lajeado, RS: Ed. da Univates, 2017.

BERBEL, Neusi. As metodologias ativas e a promoção da autonomia dos estudantes. Semina: Ciências Sociais e Humanas, Londrina, v. 32, n. 1, p. 25-40, jan./jun. 2011.

CHASSOT, Attico. Alfabetização Científica: questões e para desafios para a educação. 8a Edição. Ijuí, Unijuí, 2018.

FONSECA, Franciele Fagundes et all. As vulnerabilidades na infância e adolescência e as políticas públicas brasileiras de intervenção. Rev Paul Pediatr 2013;31(2):25864. Disponível em< http://www.scielo.br/scielo.php?script=sci_arttext\&pid=S0103$05822013000200019>$ Acessado em fev. 2019. 
MATTAR, João. Metodologias ativas: para a educação presencial, blended e a distância. São Paulo: artesanato educacional. 2017.

MORÁN; J. M. Mudando a educação com metodologias ativas. Coleção mídias coletâneas. 2015. Disponível em: <http://www2.eca.usp.br/moran/wpcontent/uploads/2013/12/mudando_moran.pdf>. Acesso em: 22 jun. 2018.

SILVA, Jacqueline Silva da; BEUREN, Jéssica; LORENZON, Mateus. Investigar com crianças: subsídios para a formação e trabalho docente. Lajeado - RS: Ed. da Univates, 2016.

THIOLLENT, Michel. Metodologia da pesquisa-ação. São Paulo: Cortez, 2000.

Metodologia de pesquisa-ação na prática extensionista. IV Seminário de Extensão da UFRN- Natal, 26-11-2008. Disponível em:< http://reitoria.ifpr.edu.br/wpcontent/uploads/2009/05/Palestra_Michael_Thiollent1.pdf> Acessado em fev 2019.

TRINDADE, Diamantino Fernandes. Interdisciplinaridade: Um novo olhar sobre as ciências. IN: FAZENDA, Ivani. O que é interdisciplinaridade? São Paulo: Cortez, 2008.

ZANON, Dulcimeire Ap Volante e FREITAS, Denise de . A aula de ciências nas séries iniciais do ensino fundamental: ações que favorecem a sua aprendizagem. Ciências \& Cognição 2007; Vol 10: 93-103. 